https://doi.org/10.48009/1_iis_2008_37-43

\title{
The Use of an Action Item Based System to Implement and Document Embedded Assurance of Learning Activities in Support of a School/Program's Strategy Elements
}

\author{
Orion Welch, St. Mary’s University, owelch@stmarytx.edu \\ Michele Kleckner, Elon University, mkleckne@elon.edu
}

\begin{abstract}
This paper describes the implementation of an action item based embedded assessment program to support assurance of learning in CIS/MIS programs based on school and program goals. The paper describes the instrument, the data flows, the implementation process, and the review system. The Action Item instrument is used to describe the vision elements supported, the learning objective, the success criteria, the recovery process for students not satisfying the success criteria, and the discovery component which identifies what the professor learned about curriculum and instruction as a result of the activity. It provides a very efficient and effective way to standardize an imbedded assessment program while at the same time encouraging innovation.
\end{abstract}

Keywords: assessment, assurance of learning, CIS program, continuous improvement, innovation, learning objectives, MIS.

\section{INTRODUCTION}

Palomba and Banta define the assurance of learning process as:

"The systematic collection, review, and use of information about educational programs undertaken for the purpose of improving student learning and development.” [4]

Faculty, students, and school administration each day are involved in a variety of assurance of learning activities that they may not even be aware of. The trick is in developing a systematic way of collecting, reviewing, and using the information to implement and document continuous process improvement of instruction and curriculum to support a school or program strategy elements of Vision, Mission, Themes, and Differentiators. This paper describes an example of one school/program's implementation of strategy elements and a quality improvement program to assess the academic support of the strategy elements.

\section{STRATEGY ELEMENTS}

\section{Vision Statement}

The vision statement provides a concise expression of the intentions of the school.

The School/Program will achieve Academic Excellence, National Prominence, and Premier Status. [5]

\section{Mission Statement}

The mission statement defines the purpose of the school and provides the basis of decision making by faculty, staff and administrators. The mission statement should be established through consultation with appropriate stakeholders that include students, faculty, staff, university administrators, and business leaders.

The School/Program provides academic opportunities and individualized experiences that create graduates with the following qualities: Ethical Leadership, Technical Excellence, Global Awareness, and Professional Orientation. [5]

\section{Themes}

Themes serve to define and focus activities within the school for faculty, staff and administrators.

The four themes at the School/Program are: Ethical Leadership, Technical Excellence, Global Awareness, and Professional Orientation. [5]

Themes are not mutually exclusive but can be considered exhaustive. Activities which address one or more of the themes are encouraged and generally will be supported with intellectual capital and school resources. The themes must be consistent with and complement the University mission. 


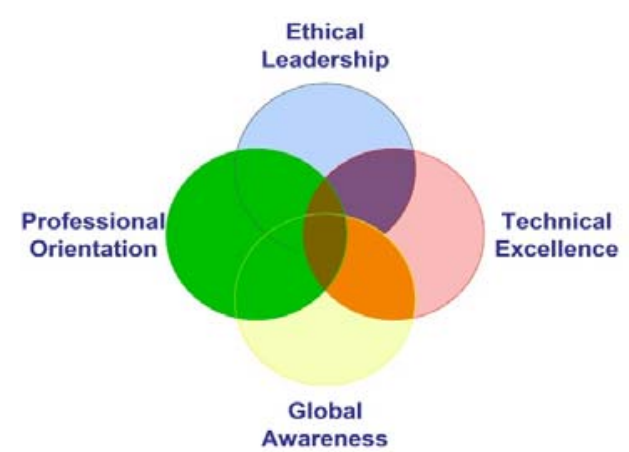

The use of themes, which are broad statements, precludes the need to establish specific objectives prior to any activity. Instead, any activity that translates a theme into a learning objective may be pursued subject only to any approvals specified in the Action Item Process (see below). [5] Themes provide the school with a continuous, rather than periodic, approach to strategic decision making. These themes are self-defining in that the definition of each is provided in the collection of Action Items learning objective that support the theme. Allowing the themes to be defined by the Action Items allows the interpretation of each theme to be dynamic and responsive to change.

Themes may be revised, eliminated, or new themes may be added as a part of a revision to the school's mission statement. The criteria for themes should be:

- Distinctive: Providing profitable differences

- Selective: Providing information about what not to do

- Suggestive: Guiding rather than prescribing strategies and actions

- Few And Short: Easily remembered

- Applicable To Students, Faculty And Staff: Providing consistency throughout the school/program

- Fit Together: Complementary to each other

\section{Differentiators}

Differentiators are qualities that distinguish the school from other institutions. While any single differentiator may be found at other schools, the differentiators should be viewed as a set of desirable attributes.
The differentiators for the School/Program are:

Academic Opportunities: A unique set of educational endeavors that provide students, faculty, and/or staff with enriching activities or events and,

Individualized Experiences: A unique set of educational endeavors that center on the individual interests, skills, or abilities of students, faculty, and/or staff. [5]

\section{COLLECTING INFORMATION}

\section{The Action Item Template}

Action Items are documented activities that support the Vision, Mission and/or Differentiators of the school. Action Item activities are described on an Action Item Template (shown below) and the resulting document is used for one or more of the following purposes: (1) notify supervisors of planned activities, (2) document mission support activities for review and analysis to support Assurance of Learning and/or (3) document activities that require funding. [5]

\begin{tabular}{|c|c|}
\hline \multicolumn{2}{|c|}{ ACTION ITEM TEMPLATE } \\
\hline IDENTIFICATION & [automatically assigned] \\
\hline \multirow{2}{*}{$\begin{array}{l}\text { COURSE-RELATED } \\
\text { ACTIVTYY }\end{array}$} & Is this Al course related? COURSE SECTION SEMESTER YEAR \\
\hline & No $\square$ Yes \\
\hline \multicolumn{2}{|l|}{ TITLE } \\
\hline VISION SUPPORT & $\begin{array}{l}X \text { Academic Excellence } \\
X \text { National Prominence } \\
X \text { Premier status }\end{array}$ \\
\hline THEME SUPPORT & $\begin{array}{l}X \text { Ethical Leadership } \\
\square \text { Technical Excellence } \\
\square \text { Global Awareness } \\
X \text { Professional Orientation }\end{array}$ \\
\hline CONTACT PERSON & s. Sam Sedki \\
\hline \multicolumn{2}{|l|}{ ACTIVTT } \\
\hline \multicolumn{2}{|l|}{ SUCCESS CRITERIA. } \\
\hline \multicolumn{2}{|l|}{ RECOVERY } \\
\hline \multicolumn{2}{|l|}{ RESOURCES } \\
\hline DIFFERENTIATORS & $\begin{array}{l}\text { X This Action Item provides an enrided Academic Opportunity } \\
\square \text { This Action Item provides an Individualized Experience }\end{array}$ \\
\hline \multicolumn{2}{|l|}{ DATES } \\
\hline \multicolumn{2}{|l|}{ APPROVAL } \\
\hline DISCOVERY & \\
\hline
\end{tabular}




\section{Action Item Submission}

Action Items must be written and approved for any activity requiring funding. As a general rule, an Action Item should be written for any significant activity that contributes to the Vision, Mission, and/or one or both Differentiators. Types of activities for which Action Items may be written are as follows but not limited to the list provided.

- Class-related class activities that directly support assurance of learning

- Student-related out-of-class activities that directly support the assurance of learning

- Funded or unfunded faculty-related activities that directly support vision elements

- Curriculum or process change initiatives that directly support vision elements

Each course syllabus must have at least one attached Action Item that assesses students' learning objectives against one or more theme/goal. A learning objective describes a measurable attribute in support of a theme/goal.

\section{Action Item Recording and Approval Process}

Action Items follow different approval (or documentation) processes depending upon whether they include a request for funding or not. The process for handling Action Items is diagrammed below. [5]

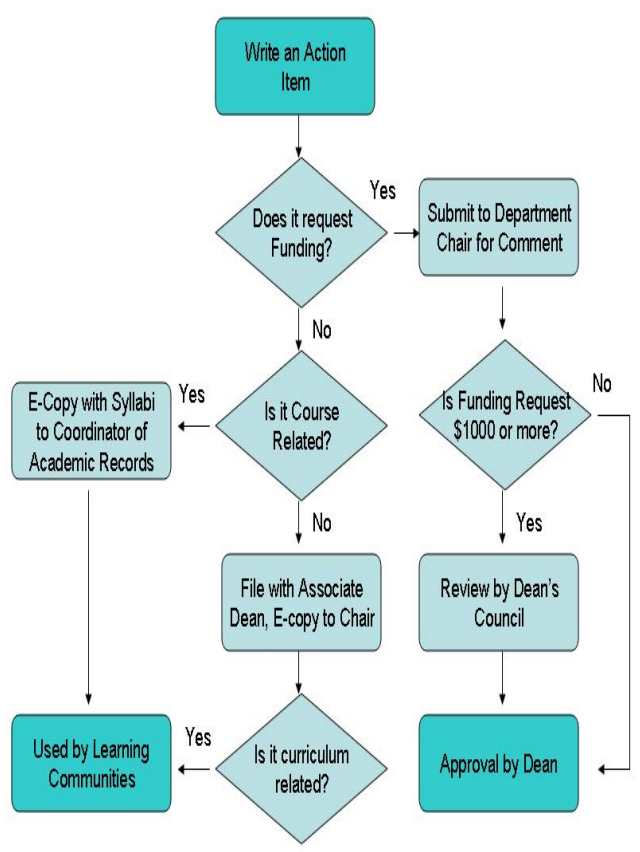

\section{REVIEW PROCESS}

\section{Closing the Loop}

An essential element of this strategic model is the creation and action of Learning Communities that will tabulate Action Items by Vision Support, Mission Support (theme) and by Differentiator. Learning communities will also analyze Action Items in a manner that supports learning and improvement within the school and will periodically report their findings to the faculty, administration, and staff.

The Action Item documents several important components of an embedded assessment program by:

- identifying the vision elements, learning goals, and differentiators that the embedded assessment learning objective supports

- identifying the resources that are required to support the activity

- describing the learning objective

- establishing a success criteria (faculty can also attach a rubric)

- identifying a recovery process for students that do not satisfy the success criteria

- requiring the faculty to include a discovery component that identifies what changes they will make in that specific course as a result of the assessment activity and what shortcoming in program curriculum, if any, was identified.

The discovery element is the key to successful implementation of an embedded assessment program. It documents the course quality improvement initiatives. It also documents possible deficiencies in core curriculum for discussion and quality improvement actions. In addition, the aggregate Action Items provide a wealth of information on the creative activities involving students. Finally, it provides a record trail of the resources the school has spent on assessment activities against the various learning goals.

While the discussion in this case is focused on course embedded assessment activities, the Action Item form can also be used to capture assessment activity outside the classroom including student club activities and competition teams that the school/department sends out to regional and national competitions. 


\section{Examples of Action Item Activities for CIS/MIS Classes}

The following provides some examples of various types of embedded Action Item learning objective type activities.

\section{Ethical Leadership}

\section{Activity}

Students will be required to provide a write up on an IT ethical case framing the discussion on the concepts they learned in their foundational ethics class.

\section{$\underline{\text { Success criteria }}$}

Students will be able to identify the ethical issue and provide a position demonstrating formulation of a personal ethical framework.

\section{Recovery}

Ethics chair will hold a work shop with students that did not meet the success criteria to discuss and review the case.

\section{Discovery}

Students appeared to have trouble applying ethical frameworks to a case involving corporate social responsibility regarding workers when closing a plant.

\section{Technical Excellence}

\section{Activity}

Students are able to take their course syllabus and develop an Excel based spreadsheet that will accurately calculate their real time grade in each of their classes.

\section{$\underline{\text { Success criteria }}$}

Students will be successful implementing spreadsheet.

\section{Recovery}

Tutoring by other students until successful.

\section{Discovery}

Students were able to develop the mathematical expression but had trouble coding it into Excel. Need to discuss with math department to include Excel exercises in freshmen math classes.

\section{Professional Orientation}

Activity

Students will conduct a fashion show wearing clothes they would wear to a job or internship interview. External fashion consultant will critique.

\section{Success criteria}

Student's dress will meet acceptable standard for an interview with minor suggestions from the consultant.

\section{Recovery}

Students judged by the consultant as needing to rethink their attire will advise instructor when corrections have been made.

\section{Discovery}

Recurring issues were color selection, length of skirts, and dress too casual, nice for parties but not for interviews.

\section{Global Awareness}

\section{Activity}

Students will write a two page paper illustrating how a local company has implemented one of the "flattener's" described in the World is Flat.

\section{Success criteria}

Student paper will correctly apply the concept tin a real world example.

\section{Recovery}

Instructor will provide a written critique of the paper and request a rewrite until the student has correctly applied a "flattener" concept.

\section{Discovery}

Students were mostly successful in applying the concept. Enjoyed the book World is Flat better than their text according to evaluation comments. They also liked the research exposure to local company information versus "international" companies. 


\section{The Quality Improvement Process}

The Association to Advance Collegiate Schools of Business, AACSB, issued a white paper in November 2007 that identified five steps in establishing an effective assurance of learning program.

1. Definition of student learning goals and objectives

2. Alignment of curricula with adopted goals

3. Identification of instruments and measures to assess learning

4. Collection, analyzing, and dissemination of assessment information

5. Using assessment information for continuous improvement including documentation that the process is being carried out in a systematic, ongoing basis. [1]

The proposed Action Item process supports the last 3 steps of the assurance of learning program. The AACSB white paper suggests assurance of learning can be demonstrated through stand-alone testing/performance and course-embedded instruments. One approach is to treat instructional effectiveness and outcome performance improvement as a collective effort and responsibility.

The suggested approach is to use stand-alone type testing and performance measurements such as the national level Major Field Assessment Test (MFAT), which measures general knowledge in nine discipline areas including information system, quantitative analysis, international business as well as others. Instruments such as Foundation's Capstone Simulations can measure team performance of students in business simulations. Finally, the proposed Action Items instrument provides documentation of course embedded learning objectives.

Under this combined assessment program, faculty would meet as a group in their discipline areas once each semester to conduct a systematic review of the results of a variety of assessment instruments. An overview would be presented of the results of the stand alone testing and the weaknesses observed in the simulations conducted in the various classes. Standards for percentile rankings against other programs would be established such as $90^{\text {th }}$ for excellence and $70^{\text {th }}$ for satisfactory. Curriculum knowledge gaps would be examined and quality improvements implemented. Overall performance of CIS/MIS majors could be reviewed across all tested areas and performance of all students could be reviewed in Quantitative Analysis \& Information Systems.
MFAT Results Information Systems Majors

\begin{tabular}{|c|c|c|c|c|c|}
\hline \multirow{2}{*}{ Discipline Tested } & \multicolumn{5}{|c|}{ Percentile Rank } \\
\hline & $\underline{\text { FL05 }}$ & SP06 & FL06 & SP07 & FL07 \\
\hline Accounting & $40^{\text {th }}$ & $60^{\text {th }}$ & $50^{\text {th }}$ & $35^{\text {th }}$ & $25^{\text {th }}$ \\
\hline Economics & $55^{\text {th }}$ & $40^{\text {th }}$ & $20^{\text {th }}$ & $35^{\text {th }}$ & $45^{\text {th }}$ \\
\hline Management & $20^{\text {th }}$ & $40^{\text {th }}$ & $30^{\text {th }}$ & $55^{\text {th }}$ & $40^{\text {th }}$ \\
\hline \multicolumn{6}{|c|}{ Quantitative Analysis \& } \\
\hline Information Systems & $90^{\text {th }}$ & $90^{\text {th }}$ & $80^{\text {th }}$ & & \\
\hline \multicolumn{4}{|c|}{ Quantitative Analysis \& } & $75^{\text {th }}$ & $70^{\text {th }}$ \\
\hline \multicolumn{4}{|c|}{ Information Systems } & $90^{\text {th }}$ & $90^{\text {th }}$ \\
\hline Finance & $60^{\text {th }}$ & $50^{\text {th }}$ & $65^{\text {th }}$ & $65^{\text {th }}$ & $50^{\text {th }}$ \\
\hline Marketing & $80^{\text {th }}$ & $75^{\text {th }}$ & $40^{\text {th }}$ & $60^{\text {th }}$ & $90^{\text {th }}$ \\
\hline Legal/Social Environ. & $50^{\text {th }}$ & $40^{\text {th }}$ & $70^{\text {th }}$ & $30^{\text {th }}$ & $40^{\text {th }}$ \\
\hline International Issues & $90^{\text {th }}$ & $85^{\text {th }}$ & $35^{\text {th }}$ & $80^{\text {th }}$ & $65^{\text {th }}$ \\
\hline \multicolumn{6}{|c|}{$\begin{array}{l}\text { Note: Since Spring 2007, Quantitative Analysis \& Informatio } \\
\text { Systems percentiles are reported separately. }\end{array}$} \\
\hline \multicolumn{6}{|c|}{ MFAT Results All Students } \\
\hline \multicolumn{6}{|c|}{ Discipline Tested $\quad$ Percentile Rank } \\
\hline & FL0 & SP06 & FL06 & SP07 & FL07 \\
\hline \multicolumn{6}{|c|}{ Quantitative Analysis \& } \\
\hline Information Systems & $60^{\text {th }}$ & $790^{\text {th }}$ & $780^{\text {th }}$ & & \\
\hline \multicolumn{4}{|c|}{ Quantitative Analysis \& } & $55^{\text {th }}$ & $60^{\text {th }}$ \\
\hline Information Systems & & & & $65^{\text {th }}$ & $70^{\text {th }}$ \\
\hline
\end{tabular}

An overview of the distribution of the various Action Items by discipline and theme would be presented. The purpose in this case is to discuss the distribution gaps and encourage faculty in the discipline to embed more assessment activity where theme/goal coverage is sparse. In the example shown below, the faculty would be expected to discuss ways to embed Action Items that explored learning objectives against other themes/goals besides Technical Excellence.

\section{INFORMATION SYSTEMS \& QUANTITATIVE METHODS}

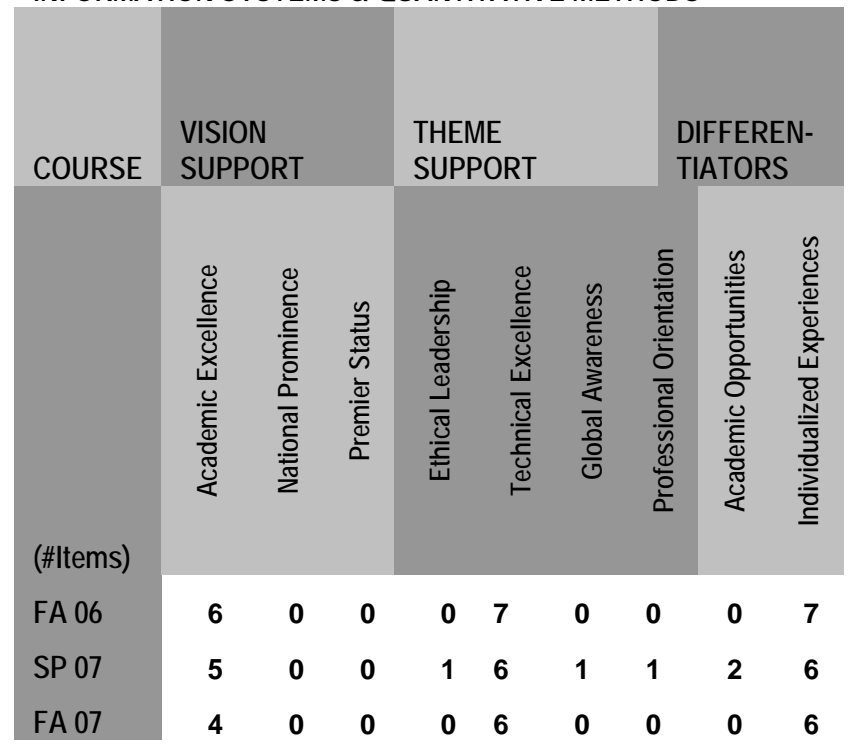

As part of the assessment meeting each faculty member would bring the completed form below documenting the quality improvements in courses and curriculum as a result of the assurance of learning activities. The department chairs would consolidate the input and prepare a report to the Dean that consolidates the quality improvement activities. 


\begin{tabular}{|l|l|}
\hline $\begin{array}{l}\text { Prior to the faculty } \\
\text { meeting in October } \\
\text { 2007 what } \\
\text { curriculum or } \\
\text { instructional } \\
\text { changes have you } \\
\text { made to courses } \\
\text { you teach? }\end{array}$ & $\begin{array}{l}\text { Please identify what } \\
\text { prompted this change } \\
\text { (e.g., MFAT results, } \\
\text { input from students via } \\
\text { faculty evaluations, } \\
\text { Action Item discovery, } \\
\text { departmental discussion, } \\
\text { your own knowledge of } \\
\text { needs in content area, } \\
\text { AACSB expectations, } \\
\text { identified gap in theme } \\
\text { coverage, academic } \\
\text { competitions RISE, SIFE, } \\
\text { etc. and other) }\end{array}$ \\
\hline $\begin{array}{l}\text { Course: } \\
\text { Change: }\end{array}$ & \\
\hline $\begin{array}{l}\text { Course: } \\
\text { Change: }\end{array}$ & \\
\hline Course: \\
Change:
\end{tabular}

\section{INSTITUTIONALIZING THE PROCESS}

One of the criticisms that might be raised against this program would be the lack of control in the assessment process. If the learning objective attributes and rubrics are being designed in the individual courses, then how can the school/program and outside reviewing agencies be assured that the overall learning outcomes are being satisfied? The issue becomes a balance of freedom of innovation versus standardization and control. The argument for innovation is it creates a great variety of measurable learning objective attributes. The Action Item process also directly addresses the faculty member who claims "I do assessment every time I walk into the classroom". Well prove it. This approach allows creativity but is subject to a peer review process by their colleagues as part of the review meetings. The process of defining, measuring, recovering, and discovering produces continuous improvement in the individual student, curriculum, and instruction. The peer driven programmatic review twice a year provides oversight over the process. The program provides a rich environment of goal oriented learning experiences to help students develop the desired qualities identified in the mission statement.
This concept of continually encouraging innovation in the creation and assessment of goal attributes supports the concept of a blue ocean strategy model. Blue ocean strategies are based on a book by Kim and Mauborgne. [3] They propose that organizations look at their traditional processes from a value innovation process. An example they site is Cirque $\mathrm{du}$ Soleil. They have been able to redefine the concept of what a circus is and to continually evolve it through innovation change. Activities that go on, such as juggling, aerial artists, and tumbling, are the same activities that are performed at a traditional circus but each show has a different intellectual sophistication and artistic richness. On a much smaller scale, the proposed embedded assessment program allows the faculty intellectual and artistic freedom in defining and looking at the distinctive mission elements of a school/program.

The issue of standardization and control can be supported within this process by implementing pre and post tests of the stand alone instruments. For instance the MFAT practice exam can be administered at multiple points in the students' progress through the curriculum.

The school/program should create learning communities of faculty for each theme/goal. The role of these learning communities would be to examine the action items for common attributes and rubrics that as a whole are defining the theme. Common Action Items and rubrics identified by the learning communities can be discussed as part of the review process in the semi annual assessment meetings. The learning communities can propose use of these targeted action items across classes to look at specific goal attributes in more depth while still allowing the faculty freedom to create other attributes. These targeted action items can be changed from year to year based on shifts in faculty emphasis focus observed by the learning communities. There can even be a multiple theme focus. For example, a learning objective that focuses on the correct business dress (professional orientation) in different cultural settings (global awareness) can be a research activity at a lower division class and next year a fashion show activity in an upper division international business class.

\section{CONCLUSION}

The Assurance of Learning assessment program described in this paper has been in use at the example school for two years. The simplified self documenting program has gained wide acceptance by the faculty and has also been proven to be useful in 
documenting use of resources in other areas in addition to course embedded activities. These include faculty development, student academic related competitions, service based learning activities, and student club activities. Another great strength, especially in the beginning, is it allows creativity in identifying various types of learning objectives and assessment activities against the goals. As the program matures the school can institutionalize some of the Action Items that have proven useful for longer term tracking while still allowing room for continuous innovation. And as Hodson and Thomas state, "if quality assurance systems are to recognize the increasingly diverse nature of higher education institutions in the new millennium, compliance will need to be balanced by a greater emphasis on encouraging innovation and self-improvement.” [2]

\section{REFERENCES}

1. Accreditation, White Papers, AACSB Assurance of Learning Standards. (2007, November 20). Retrieved February 24, 2008, from AACSB International: http://www.aacsb.edu/accreditation/papers/index. asp
2. Hodson, P., \& Thomas, H. (2003, April Volume:45, No. 3). Quality Assurance in Higher Education: Fit for the New Millennium or Simply Year 2000 Compliant? Higher Education, pp. 375-387.

3. Kim, W., \& Mauborgne, R. (2005). Blue Ocean Strategy. Boston: Harvard Business School Press.

4. Palomba, C., \& Banta, T. (1999). Assessment Essentials: Planning, Implementing, and Improving Assessment in Higher Education. San Francisco: Jossey-Bass.

5. Priesmeyer, R., Welch, O. et al (2006). Bill Greehey School of Business Faculty Guide, St. Mary’s University, San Antonio TX.

6. Stensaker, B. (2007). Impact of quality processes, Embedding Quality Culture in Higher Education, EUA Case Studies, pp. 59-62. 